Postprint of: Pérez, A.G., García-Rodríguez, R., Sanz, C. and Refoyo, A. (2017). A10-48-3 and A7-32-10, two strawberry selections with well-balanced nutritional and organoleptic quality. Acta Hortic. 1156, 363-370

The original publication is available at:

https://doi.org/10.17660/ActaHortic.2017.1156.55

\title{
A10-48-3 and A7-32-10 two strawberry selections with well-balanced nutritional and organoleptic quality
}

\author{
A.G. Pérez ${ }^{1}$, R. García-Rodríguez ${ }^{1}$, C. Sanz ${ }^{1}$ and A. Refoyo ${ }^{2}$ \\ ${ }^{1}$ Instituto de la Grasa, (CSIC), Sevilla, Spain, agracia@cica.es; ${ }^{2}$ Fresas Nuevos Materiales S.A, \\ Huelva, Spain,arefoyo@fresasnm.com
}

\begin{abstract}
In the last few years organoleptic and nutritional traits have become the major breeding targets in most strawberry breeding programs all over the world. Furthermore, the joint improvement of the nutritional value and the sensory key parameters of strawberry might increase the consumption rate of this fruit, which in turn will have a positive effect on consumer's health and a positive economic impact on the producing areas. New cultivars and strawberry selections bred in Huelva (Southwestern Spain) have been characterized in relation to their organoleptic and nutritional properties. Key metabolites associated to the strawberry flavor (sucrose, fructose, glucose, malic and citric acid and 20 main volatile compounds) as well as specific phytochemicals (nine phenolic compounds plus vitamin C) with relevant antioxidant capacities have been analyzed by high resolution gas chromatography coupled to mass spectrometry (HRGC-MS) and high performance liquid chromatography (HPLC). Data were analyzed using principal component analysis (PCA) and Pearson correlations to discriminate those strawberry selections that, besides good agronomic performances, produce fruits with high contents of key flavor components and health-promoting phytochemicals. PCA clearly distinguish selections A10-48-3 and A7-32-10 as having significantly different metabolic profiles and displaying the highest contents of sugars, organic acids, ethyl esters, mesifurane, terpineol, quercetin and vitamin $\mathrm{C}$.
\end{abstract}

Keywords: Fragaria $\times$ ananassa, flavor, nutritional quality, sugars, vitamin C, phenolic compounds, volatile compounds.

\section{INTRODUCCTION}

The continuous increase in the demand for fresh strawberry fruits may be attributed not only to the exceptional flavor of this fruit but also to its nutritional properties. Thus, strawberry breeders initially focused on the improvement of agronomical or qualitative traits, like size, number, yield, ripening, and firmness of fruit while in the last few years, organoleptic and nutritional traits have become the major breeding targets for the commercial strawberry (Diamanti et al., 2012). The development of new berry varieties thorough new breeding programs specifically focused on improving 
organoleptic and nutritional quality, requires the identification of appropriated chemical markers to measure those quality parameters. In these sense, strawberry taste, aroma and nutritional value are the most valuable factors in terms of satisfaction of consumers (Pérez and Sanz, 2008; Leon et al., 2009). Strawberry taste is basically determined by soluble sugars and organic acids (Kruger et al., 2012). These compounds could also be used as fruit maturity indices or quality markers during postharvest handling. The characteristic aroma of strawberry is determined by a complex mixture of volatile compounds and depends essentially on the particular balance between the green and fruity notes associated to six carbons aldehydes, alcohols and volatile esters, and the floral and caramel like notes provided by compounds such as benzaldehyde, linalool, terpineol or mesifurane (Pérez and Sanz, 2010; Ubeda et al., 2012). From a nutritional point of view the strawberry is an excellent source of dietary fiber and fructose, which may contribute in regulating blood sugar levels, it is one of the richest fruits in vitamin $\mathrm{C}$ and folate and it also has a very complex phenolic profile which includes anthocyanins, flavonols and hidroxicinnamic acids (Giampieri et al., 2014). Over the past ten years Spain has occupied the third place among strawberry top producers, with the area of Huelva accounting for $95 \%$ of the national production. A few years ago a strawberry breeding program was initiated by FNM in Huelva (Spain) with the aim of obtaining strawberry varieties which could meet the needs of the local sector and the increasing quality requirements of the European markets. The aim of the present work was to evaluate the organoleptic and nutritional quality of two selections recently obtained in this program by comparing their metabolic profile (sugars, organic acids, phenolic compounds and volatile compounds) against Primoris and Sabrina, two control cultivars widely planted in Southwestern Spain which have been recently selected at FNM and Planasa's research nurseries in Huelva.

\section{MATERIALS AND METHODS}

\section{Plant material and growing conditions}

Strawberry plants were grown in open-field conditions at an experimental farm located in Gibraleón (Huelva). Plants, from high-elevation nurseries, were planted on October onto two-row raised beds covered with black polyethylene mulch (distance between the plants in the row 25 to $30 \mathrm{~cm}$ ). In December the crop was covered either with small tunnels and transparent film. A randomized complete block design with three replicates (40 plants per replicate) was used. Fruit harvesting occurred at commercial ripeness (75\% of red color). Three harvesting dates per season were established: (I) March; (II) April and (III) May.

\section{Evaluation of agronomic and physicochemical quality parameters}

For each cultivar total marketable yield (grams produced per plant from first January to end of May) and percentage of first class fruit in total yield were calculated. Additionally, three physicochemical quality indexes were also measured: fruit firmness with a $3 \mathrm{~mm}$ tip dynamometer, total soluble solids (Brix ${ }^{\circ}$ ), and internal color according to the CIREF scale.

\section{Extraction, fractionation and analysis of sugars, organic acids and phenolic compounds}

Major sugars, organic acids, and phenolic compounds were extracted and fractionated according to a previously developed procedure slightly modified (Perez et al., 1997). Two replicates of approximately $700 \mathrm{~g}$ of fruit per cultivar were analyzed on each sampling date. Using the previously mentioned methodology two ethanolic extracts were obtained for each replicate. $5 \mathrm{ml}$ aliquots of the ethanolic extract were evaporated in the dark to dryness at $50^{\circ} \mathrm{C}$ and the dry residue was redissolved in $1 \mathrm{ml}$ of $0.2 \mathrm{~N} \mathrm{H} 2 \mathrm{~S} 04$ containing $0.05 \%$ EDTA, and loaded onto a previously conditioned Cl8 Sep-Pak cartridge (Supelco, Bellefonte, PA). Sugars and organic acids were eluted with up to $4 \mathrm{ml}$ of the same 
solution. After complete drying of the column phenolic compounds were eluted with $2 \mathrm{ml}$ of methanol. Extracts were filtered through $0.45 \mathrm{pm}$ Nylon filters before HPLC analysis.

Sugars and organic acids (including vitamin $\mathrm{C}$ ) were analyzed according to Pérez et al., (1997) using a Beckman Coulter liquid chromatography system equipped with a System Gold 168 detector, a solvent module 126 and a Jasco RI 2031 differential refractometer connected in series. Isocratic separations of the compounds were done on a stainless steel Ion-300 (300 x $7.8 \mathrm{~mm}, 10 \mathrm{~mm})$. On each sampling day, four extracts per treatment were analyzed.

Phenolic compounds were analyzed according to the method of Gil et al. (1997) slightly modified. Separation of the phenolic compounds was done in a Beckman Coulter liquid chromatography system equipped with a System Gold 168 detector, a solvent module 126 and a stainless steel Merck Superspher RP-18 (250 x $4 \mathrm{~mm}$ ) column using water (2.5\% formic acid) and methanol (2.5\% formic acid) as mobile phases.

\section{Analysis of volatile compounds}

15-20 halves of strawberries were blended to obtain a fruit puree for each replicate, on each sampling date. Three vials containing $2 \mathrm{~g}$ of each strawberry puree and 2 $\mathrm{ml}$ of a saturated $\mathrm{CaCl}_{2}$ solution added for enzyme inactivation were stored at $-20^{\circ} \mathrm{C}$ until analysis. Volatiles were adsorbed on a SPME fiber DVB/Carboxen/PDMS 50/30 (Supelco Co., Bellefonte, PA) at $40^{\circ} \mathrm{C}$ and further analyzed using a HP-6890 gas chromatography apparatus with a FID detector (Agilent Technologies) equipped with a DB-Wax fused silica capillary column $(60 \mathrm{~m} \times 0.25 \mathrm{~mm}$ i.d., film thickness $0.25 \mu \mathrm{m}$; J\&W, Scientific, Folsom, CA, USA). Compound identification was carried out on a Hewlet-Packard HRGC-MS 5975 series MSD equipped with the same column and oven program. Identification was done by matching against the Wiley/NBS Library and by GC retention time against standards.

\section{Statistical analysis}

Data were statistically evaluated using STATISTICA (Statsoft Inc., Tulsa, OK, USA).

\section{RESULTS AND DISCUSSION}

\section{Agronomic and physicochemical quality parameters}

Although the main goal of this study was to evaluate the nutritional and organoleptic properties of new strawberry cultivars bred in Southwestern Spain, basic agronomic and physicochemical quality indexes such as total yield, percentage of first class fruit, firmness, internal color and soluble solids content were also assessed. Sabrina, and A10-48-3 showed significantly $(\mathrm{p} \leq 0.05)$ higher yield per plant among the studied cultivars with $1269 \mathrm{~g} /$ plant and $1310 \mathrm{~g} /$ plant respectively. Among both cultivars A10-483 has a significantly higher percentage of first class fruit with $93 \%$ while the lowest value was found for Sabrina with $85 \%$ while intermediate values were found for A7-32-10 $(88 \%)$ and Primoris (89\%). Non-significant differences were found in terms of firmness, but very clear differences were found in the soluble solids content with the highest value found for A7-32-10 (10.6 ${ }^{\circ}$ Brix), followed by A10-48-3 (10.4 ${ }^{\circ}$ Brix), Primoris (10.4 ${ }^{\circ}$ Brix) and Sabrina (9.4 ${ }^{\circ}$ Brix).

\section{Sugars, organic acids and phenolic profiles.}

Data on the sugar and organic acids composition of the fruits are presented in figures 1 and 2 . The maximum ${ }^{\circ}$ Brix values obtained by A7-32-10 are confirmed by its high sugar content at the first harvesting date $(75.1 \mathrm{mg} / \mathrm{g}$ FW). Only A10-48-3 had higher sugar content at this date $(80.9 \mathrm{mg} / \mathrm{g} \mathrm{FW})$. On the second harvesting date when most strawberry cultivars suffer noticeable drop in sugars, A7-32-10 is again the second selection with higher sugar levels with $53.5 \mathrm{mg} / \mathrm{g}$ FW. The relationship between the content of sugars and organic acids is optimal in this selection and the vitamin C content of the highest among all selections tested at three harvesting dates $(0.74,0.62$ and 0.64 
$\mathrm{mg} / \mathrm{g} \mathrm{FW}$, respectively). The phenolic content of the selection A7-32-10 is not very high, but extraordinarily balanced, without excessive concentration of anthocyanins, which provides an attractive orange-red color, and very high levels in some key phenolic components (Chiva-Blanch and Visioli, 2012) such as quercetin or kaempferol (Table 1).

Sugars values analyzed in the selection A10-48-3 are extraordinarily high in the early season (80.9 mg / g fruit) with sucrose content (40.6 mg / g FW) that almost duplicate those found in other cultivars. The sugar/acid ratio is excellent, surpassed only by the selection A7-32-10, and so does vitamin C content $(0.63,0.38$ and $0.62 \mathrm{mg} / \mathrm{g} \mathrm{FW})$.

The pronounced decline of sugar content observed on the second harvesting date it is probably the large production of fruits per plant of this strawberry selection. The phenolic content of A10-48-3 is very low at the first harvesting date, mainly due to its low content of pelargonidin-3-glucoside (5.81 mg/100 g FW), but the anthocyanins (cyanidin3-glucoside, pelargonidin-3-glucoside and pelargonidin-3-rutinoside) content rise to high levels in the second and third sampling date, in which this selection is among those with higher phenolic content. On the second harvesting date, it is especially remarkable the high content of ellagic acid derivatives (free ellagic acid and ellagic acid glycoside) found in this selection.

\section{Aroma profiles}

As it has been previously mentioned aroma profile of the strawberry fruit is determined by an important number of volatile compounds in which two groups of key components could be easily identified, one group (alcohols, aldehydes and short volatile esters) provides green fruity notes while a second group of compounds eluting in the final part of the chromatographic analysis imparts sweet and floral aromatic notes. In this study, 23 volatile compounds were quantitated in the studied strawberry cultivars. Data obtained are presented in Table 2 in which individual compounds are grouped according to their chemical classes. The volatile composition of the selections A7-32-10 and A10-483 are very complex, with a good balance of green-acid and sweet-fruity notes. In both cases, the content of compounds such as terpineol and mesifurane is very high. In this sense, it is especially remarkable that the highest contents of the key strawberry flavor component, mesifurane (Perez and Sanz, 2010), were found in A10-48-3 and A7-32-10.

\section{CONCLUSIONS}

Data obtained from the organoleptic and nutritional quality assessment of the cultivars Sabrina, Primoris, A10-48-3, A7-32-10 and six other selections provided by FNM (data not shown) were analyzed using principal component analysis (PCA) and Pearson correlations to obtain information on the variables that mainly influence samples differences and similarities. The first two principal components PC1 and PC2 gave Eigenvalues greater than 1.0 (5.0 and 3.57, respectively) and explained $47.5 \%$ of the total variability. PCA score and loading plots for the two principal components clearly distinguish selections A10-48-3 and A7-32-10 as having significantly different metabolic profiles. By overlapping graphs A and B in figure 3 (projection of the cases and projection of the variables on the factor plane PC1x PC2) it is evident that A10-48-3 and A7-32-10 display the highest contents of key metabolites related to the organoleptic and nutritional quality of the strawberry such as sugars, ethyl esters, mesifurane, vitamin $C$ and quercetin.

\section{AKNOWLEDGEMENT.}

We are grateful to Mar Pascual for her excellent technical assistance. This work was supported by research project Recupera 2020 financed by MINECO-CSIC with FEDER funding. 


\section{Literature cited.}

Chiva-Blanch, G., and Visioli, F. (2012). Polyphenols and health moving beyond antioxidants. Journal of Berry Research. 2, 63-71.

Diamanti, J., Capocasa, F., Balducci, F., Battino, M., Hancock, J. and Mezzettti, B. Increasing strawberry fruit sensorial and nutritional quality using wild and cultivated germplasm. (2012). Plos one, 7, e46470.

Giampieri,F., Alvarez-Suarez, J. M., and Battino, M. (2014). Strawberry and human health: Effects beyond antioxidant activity. J. Agric. Food Chem. 62, 3867-3876.

Gil M.I., Holcroft, D., and Kader, A.A. (1997). Çhanges in strawberry anthocyanins and other polyphenols in response to carbon dioxide treatment. J. Agric. Food Chem. 45, 1662-1667.

Kruger, E., Josuttis, M., Nestby, R., Toldam-Andersen, T.B., Carlen, C and Mezzetti B. (2012). Influence of growing conditions at different latitudes of Europe on strawberry growth performance, yield and quality. Journal of Berry Research. 2, 15-23.

León A.M., Torres, P., Sanz, C. and Pérez, A.G. 2009. Quality Evaluation of Processed Strawberry Fruits. Acta Hortic., 842, 935-938.

Pérez AG., Olías R., Espada J., Olías J.M., Sanz C. (1997) Rapid determination of sugars, nonvolatile acids and ascorbic acid in strawberry and other fruits. J. Agric. Food Chem., 45: 3545-3549.

Pérez, A.G. y Sanz C. (2008). Techniques for postharvest handling, storage and transport of fruit. In: The strawberry crop at Huelva. (ISBN: 978-84-8474-222-7), pp 219-244.

Pérez, A.G., and Sanz, C. (2010) Strawberry flavor (Chapter 23) In: Handbook of Fruit and Vegetable Flavors (Ed. Y.H.Hui) (ISBN 978-0-470-22721-3) pp 431-450. Wiley, New Jersey USA

Ubeda, C. , San-Juan, F., Concejero, B., Callejón, R.M., Troncoso, A.M., Morales, M.L., Ferreira, V. and HernándezOrte, P. J. (2012). Glycosidically Bound Aroma Compounds and Impact Odorants of Four Strawberry Varieties. J. Agric. Food Chem., 60, 6095-610 
Table 1. Phenolic composition.

\begin{tabular}{|c|c|c|c|c|c|c|c|c|}
\hline \multicolumn{9}{|c|}{ Mean values (mg/100g FW) } \\
\hline & Harvest date & Ellagitannins & Cyan-3-G² & Pelarg-3-G & Pelarg-3-R & Quercetin & Ellagic der. & Kaempferol \\
\hline \multirow[t]{3}{*}{ Sabrina } & 1 & $13.49 \pm 0.75^{1}$ & $0.31 \pm 0.04$ & $17.92 \pm 0.75$ & $1.21 \pm 0.10$ & $1.91 \pm 0.04$ & $1.3 \pm 0.01$ & $0.83 \pm 0.12$ \\
\hline & ॥ & $8.69 \pm 0.38$ & $0.21 \pm 0.10$ & $28.10 \pm 2.251$ & $2.36 \pm 0.08$ & $1.97 \pm 0.63$ & $1.69 \pm 0.12$ & $1.12 \pm 0.29$ \\
\hline & III & $13.81 \pm 1.84$ & $0.26 \pm 0.08$ & $28.67 \pm 1.50$ & $2.97 \pm 0.23$ & $2.10 \pm 0.22$ & $1.20 \pm 0.05$ & $1.23 \pm 0.18$ \\
\hline \multirow[t]{3}{*}{ Primoris } & 1 & $8.20 \pm 0.10$ & $0.95 \pm 0.24$ & $15.12 \pm 1.97$ & $0.83 \pm 0.14$ & $1.81 \pm 0.48$ & $1.51 \pm 0.11$ & $0.71 \pm 0.02$ \\
\hline & ॥ & $8.82 \pm 0.40$ & $1.95 \pm 0.14$ & $31.42 \pm 2.11$ & $1.85 \pm 0.13$ & $2.54 \pm 0.24$ & $1.92 \pm 0.12$ & $1.31 \pm 0.03$ \\
\hline & III & $9.24 \pm 0.16$ & $1.69 \pm 0.05$ & $24.81 \pm 0.68$ & $1.70 \pm 0.03$ & $3.53 \pm 0.04$ & $1.74 \pm 0.09$ & $1.61 \pm 0.02$ \\
\hline \multirow[t]{3}{*}{ A10-48-3 } & I & $5.05 \pm 1.19$ & $0.52 \pm 0.15$ & $5.81 \pm 1.58$ & $0.31 \pm 0.18$ & $2.24 \pm 0.56$ & $1.68 \pm 0.24$ & $0.65 \pm 0.09$ \\
\hline & $\|$ & $4.90 \pm 0.82$ & $1.15 \pm 0.04$ & $24.16 \pm 0.94$ & $1.89 \pm 0.19$ & $1.65 \pm 0.22$ & $2.01 \pm 0.14$ & $0.82 \pm 0.13$ \\
\hline & III & $4.95 \pm 0.46$ & $2.03 \pm 0.62$ & $25.10 \pm 3.97$ & $2.42 \pm 0.43$ & $2.47 \pm 0.37$ & $1.61 \pm 0.10$ & $1.02 \pm 0.21$ \\
\hline \multirow[t]{3}{*}{ A7-32-10 } & I & $3.38 \pm 0.34$ & $1.04 \pm 0.13$ & $14.95 \pm 0.11$ & $1.17 \pm 0.01$ & $2.82 \pm 0.57$ & $2.05 \pm 0.03$ & $1.14 \pm 0.15$ \\
\hline & ॥ & $1.72 \pm 0.09$ & $1.11 \pm 0.15$ & $17.86 \pm 0.92$ & $1.37 \pm 0.10$ & $2.78 \pm 0.49$ & $1.65 \pm 0.16$ & $1.02 \pm 0.16$ \\
\hline & III & $1.44 \pm 0.09$ & $0.67 \pm 0.16$ & $14.22 \pm 1.27$ & $1.47 \pm 0.23$ & $2.21 \pm 0.42$ & $1.47 \pm 0.05$ & $0.94 \pm 0.14$ \\
\hline
\end{tabular}

1Values represent the mean and standard deviation of four independent analyses

2Nine phenolic compounds were analyzed: ellagitannins, cyaniding-3-glucoside, pelargonidin-3-glucoside, pelargonidin-3-rutinoside, quercetin, ellagic acid and ellagic acid glycoside (expressed as ellagic derivatives), and kaempferol 
Table 2. Volatile composition.

\begin{tabular}{|c|c|c|c|c|c|c|c|c|c|c|c|c|}
\hline & \multirow[b]{2}{*}{$\begin{array}{c}\text { Harvest } \\
\text { date }\end{array}$} & \multicolumn{11}{|c|}{ Volatile components (area) } \\
\hline & & ethanol & hexanal & $\begin{array}{l}\text { isoamyl } \\
\text { acetate }\end{array}$ & $\begin{array}{l}\text { butyl } \\
\text { esters }\end{array}$ & $\begin{array}{l}\text { methyl } \\
\text { esters }\end{array}$ & $\begin{array}{l}\text { hexyl } \\
\text { esters }\end{array}$ & $\begin{array}{c}\text { ethyl } \\
\text { esters }\end{array}$ & benzaldehyde & linalool & mesifurane & terpineol \\
\hline \multirow[t]{3}{*}{ Sabrina } & I & 13085 & 380609 & 36548 & 2765303 & 513681 & 161447 & 223589 & 31804 & 142350 & 47365 & 134450 \\
\hline & ॥ & 393827 & 380250 & 43175 & 2378774 & 662301 & 352131 & 199928 & 19949 & 164456 & 25870 & 43431 \\
\hline & III & 30210 & 469500 & 45312 & 3803106 & 1201520 & 510370 & 543027 & 51055 & 377174 & 87406 & 418392 \\
\hline \multirow[t]{3}{*}{ Primoris } & 1 & 10940 & 378596 & 18073 & 3293915 & 803707 & 206353 & 446127 & 26810 & 220833 & 79063 & 76496 \\
\hline & ॥ & 19446 & 400133 & 25200 & 2622231 & 1034145 & 448175 & 224171 & 15049 & 233053 & 41197 & 45775 \\
\hline & III & 79607 & 207256 & 43780 & 3496548 & 994502 & 397931 & 1060596 & 39578 & 334860 & 241314 & 250495 \\
\hline \multirow[t]{3}{*}{ A10-48-3 } & I & 40041 & 303411 & 28524 & 2474979 & 317885 & 204905 & 1315041 & 29272 & 198147 & 98482 & 136539 \\
\hline & II & 33525 & 268183 & 14475 & 2140312 & 651185 & 319626 & 336964 & 1000 & 157514 & 43035 & 60427 \\
\hline & III & 83592 & 136809 & 32123 & 2074741 & 784185 & 232102 & 3710809 & 33042 & 172947 & 176108 & 411068 \\
\hline \multirow[t]{3}{*}{ A7-32-10 } & I & 18163 & 511900 & 29296 & 3112339 & 593823 & 305849 & 945215 & 25000 & 143494 & 104075 & 100338 \\
\hline & ॥ & 19695 & 524806 & 20150 & 2365303 & 561931 & 499877 & 226885 & 22782 & 155118 & 53696 & 48821 \\
\hline & III & 31805 & 838247 & 44277 & 3633260 & 946715 & 527383 & 775733 & 22937 & 195738 & 305246 & 190819 \\
\hline
\end{tabular}

${ }^{1}$ Values represent the mean of four independent analyses

2twenty three individual volatile compounds were quantitated. Volatile esters are grouped according to their alcohol moiety. 


\section{Figure 1}



Figure 1: Sucrose, fructose and glucose content (mg/ g FW) at three different harvesting dates: (I) March, (II) April and (III) May 
Figure 2

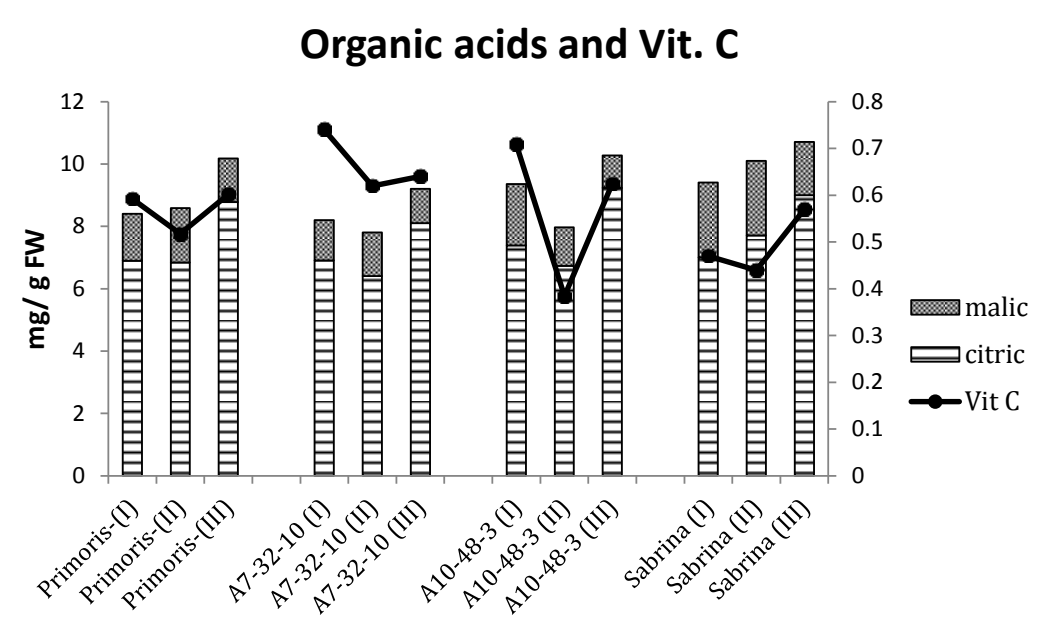

Figure 2: Content of Malic and citric acids (principal "Y"axis) and vitamin C (secondary "Y" axis) (mg/g FW) at three different harvesting dates: (I) March, (II) April and (III) May. 


\section{Figure 3}

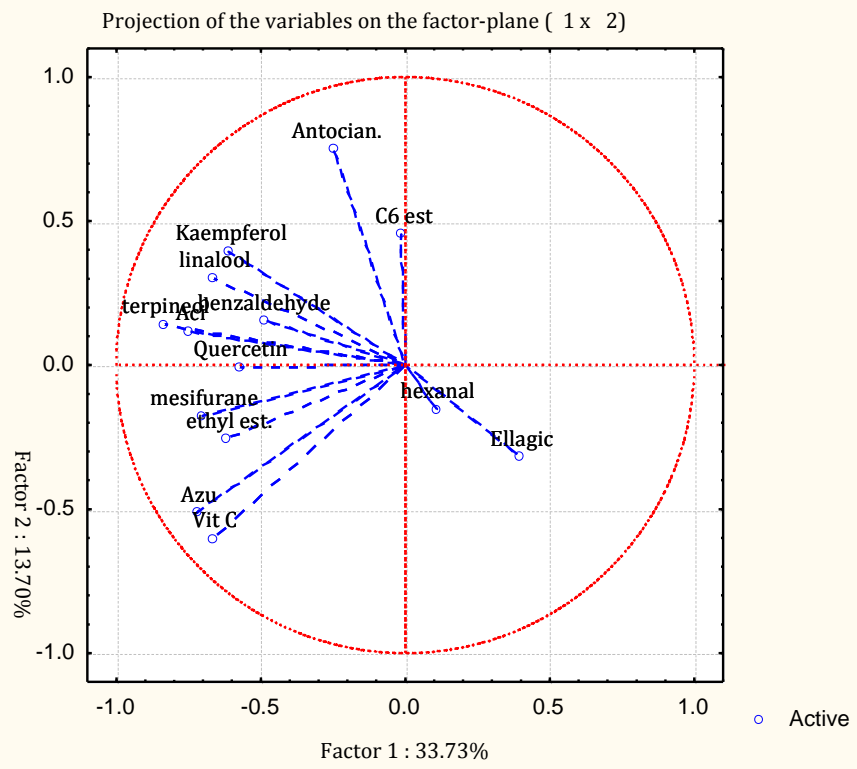

Projection of the cases on the factor-plane ( $\left.\begin{array}{ll}1 \times 2 & 2\end{array}\right)$

Cases with sum of cosine square $>=0.00$

Labelling variable: cultivar

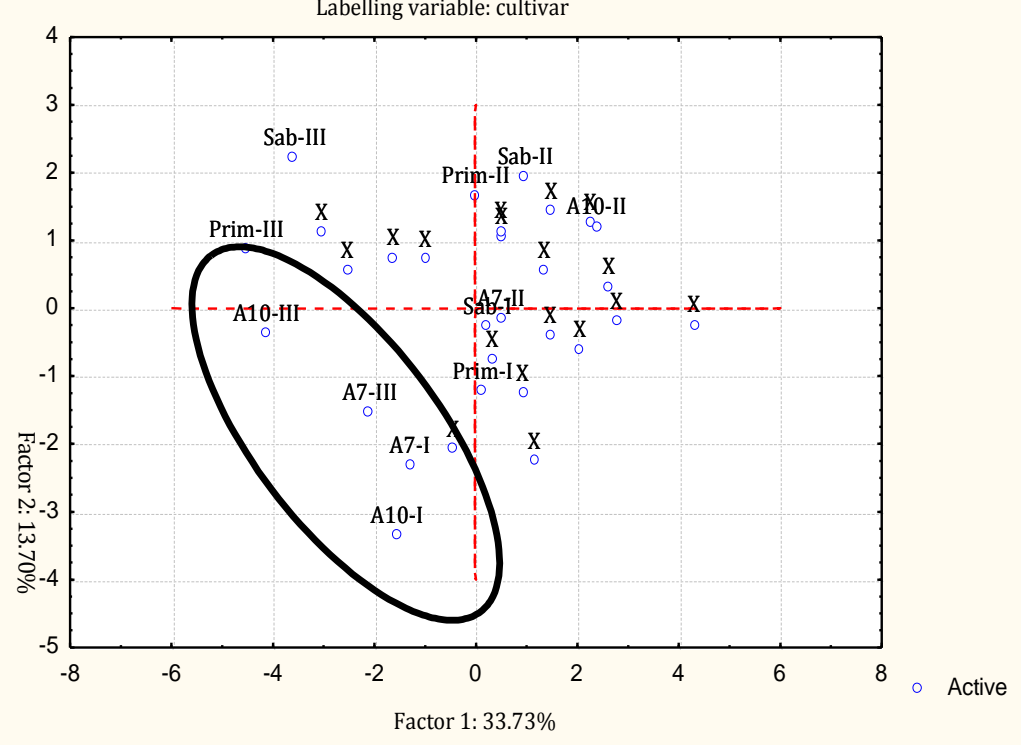

Figure 3. PCA analysis. (A) Projection of the variables the factor plane $1 \times 2$ showing the correlation of key metabolites with PC1 and PC2 and (B) Projection of the cases on the factor plane 1x2 showing the correlation of the cultivars with PC1 and PC2. 